\title{
High-performance tandem silicon solar cells on $\mathrm{F}: \mathrm{SnO}_{2}$
}

\author{
H.M. Yates ${ }^{\text {a,* }}$, P. Evans ${ }^{\text {a,b }}$, D.W. Sheel ${ }^{\mathrm{a}, \mathrm{b}}$, S. Nicolay ${ }^{\mathrm{c}}$, L. Ding ${ }^{\mathrm{c}}$, C. Ballif ${ }^{\mathrm{c}}$ \\ a Materials and Physics Research Centre, University of Salford, Manchester, M5 4WT, UK \\ b CVD Technologies Ltd., University of Salford Campus, Manchester, M5 4WT, UK \\ c EPFL STI IMT-NE PV-LAB, Photovoltaics and Thin Film Electronics Laboratory, IMT, Rue A.-L. Breguet 2, CH-2000 Neuchâtel, Switzerland
}

\section{A R T I C L E I N F O}

Available online 27 May 2013

\section{Keywords:}

Tin oxide

Atmospheric pressure chemical vapour

deposition

Water concentration

Solar cell

a-Si:H

Micromorph

\begin{abstract}
A B S T R A C T
High-performance transparent conducting oxides (TCOs) have significance for optimising PV performance. The efficiency of the resulting solar cells is dependent particularly on achieving high light scattering, low resistivity and low absorption (via low free carrier absorption), in addition to suitable surface morphology for absorber growth quality. These properties have been targeted by systematic exploration of the Atmospheric Pressure Chemical Vapour Deposition (APCVD) growth parameters, in particularly the effect of the tin precursor to water ratio.

Using the APCVD process F-doped $\mathrm{SnO}_{2}$ has been deposited on glass using monobutyl tin trichloride with trifluoro-acetic acid as the dopant source. Experiments established that an increased water to tin precursor ratio gave smaller surface features, along with increased electrical mobility and optical transmittance at high reactant ratios. Samples were then used in manufacture of thin film solar cells, which showed enhanced performance, in comparison to commercially available TCO CVD coated glasses, with high quantum efficiency yield. In particular, high water to tin precursor ratios led to much improved open circuit voltages, fill factors and high current densities within the cells. Tandem cells with efficiencies of $10.75 \%$ were achieved, which were higher than those produced concurrently using commercially available TCO both on-line $9.50 \%$ and off-line $10.20 \%$.
\end{abstract}

(C) 2013 Elsevier B.V. All rights reserved.

\section{Introduction}

Transparent conducting oxides (TCOs) are widely used throughout industry and in particular in the production of solar cells where front electrical contacts are needed which are highly optically transparent and with a relatively low electrical resistance [1]. The properties of this TCO front contact have been shown to be critical to the performance of the thin film solar cells. To optimise the cell efficiency many competing factors need to be considered such as the need for a rough surface with a particular feature type [2] to enhance light scattering, which in turn will increase the current density within the cell and improve performance [3]. It has previously been reported that the morphology of the TCO can induce defects within amorphous [4] or microcrystalline [5] silicon absorber layers. Surface roughness also decreases the fill factor, FF, and open circuit voltage, $\mathrm{V}_{\mathrm{oc}}$, which could reduce cell efficiency, so a balance of conditions is required.

Atmospheric Pressure Chemical Vapour Deposition (APCVD) is an excellent technique to use to deposit suitable TCO films as by careful choice of the deposition parameters the resulting film can be tailored for specific characteristics. APCVD processes are particularly suited to

\footnotetext{
* Corresponding author. Tel.: +44161295 3115; fax: +44 1612955575. E-mail address: H.M.Yates@Salford.ac.uk (H.M. Yates).
}

use in industry due to the high volume, continuous growth processes and fast growth rates achievable [6]. For example, in-line deposition during float glass production.

Previous work with F-doped $\mathrm{SnO}_{2}$ established that although it was possible to change surface morphology by use of different APCVD parameters such as deposition time [7], tin precursor [8], additives $[9,10]$, temperature or growth rate [11] these all could have strong and sometimes adverse effects on the optical or electrical properties of the thin films. In this paper different water to tin precursor ratios were investigated in the deposition of $\mathrm{SnO}_{2}: \mathrm{F}$ as it has previously been shown that water is an efficient precursor with a different $\mathrm{TCO}, \mathrm{ZnO}$, for finely tuning the film surface while keeping good electrical and optical properties [12].

This series of APCVD deposited $\mathrm{SnO}_{2}: \mathrm{F}$ thin films was then used to fabricate hydrogenated amorphous silicon (a-Si:H) single junction cells. Following on from this a new set of $\mathrm{SnO}_{2}: \mathrm{F}$ films was produced based on the most promising cell test results. These samples, along with two commercially available TCO samples (both on-line and off-line products) were used in fabrication of micromorph tandem cells. These consist of both a-Si:H and microcrystalline silicon ( $\mu c-\mathrm{Si}: \mathrm{H})$ layers in which a part of the light that is transmitted by the a-Si:H top cell is absorbed by the $\mu c$-Si bottom cell. These give greater efficiency in use of the received sunlight as $\mu \mathrm{c}$-Si:H solar cells have a higher absorption compared to a-Si:H in the wavelength range from 800 to $1100 \mathrm{~nm}$. 


\section{Experimental details}

\subsection{TCO growth}

The $\mathrm{SnO}_{2}: \mathrm{F}$ was deposited by APCVD at $600{ }^{\circ} \mathrm{C}$ using monobutyl tin trichloride (MBTC) with $0.2 \mathrm{M}$ aq. Trifluoro-acetic acid (TFAA) delivered at a range of $\mathrm{Sn}$ precursor to $\mathrm{H}_{2} \mathrm{O}$ molar ratios. Precursors were vapourised using either bubbler (MBTC at $125^{\circ} \mathrm{C}, 0.41 \mathrm{~min}^{-1}$ carrier gas, $5.72 \times 10^{-4} \mathrm{~mol} \mathrm{~min}^{-1}$ ) or flash evaporation (TFAA/water mix). Nitrogen was used as the carrier gas, with $20 \%$ oxygen at a total flow of $2 \mathrm{l} / \mathrm{min}$. Deposition was on $1 \mathrm{~mm}$ thick borosilicate (Corning Eagle 2000) glass. An APCVD gas handling system combined with an in-house designed coater head system was employed to deliver precursors to the surface of the substrate. On this system the heated substrate is translated on an automated stage, beneath a static, non-contact gas distributor in an extracted, open atmosphere, enclosure. This allows the deposition of extended area films with high uniformity over $100 \mathrm{~mm}$ width $( \pm 2 \%)$ and the length only limited by the translation table size. The number of substrate passes under the CVD coating head was adjusted to maintain constant film thickness of about $1000 \mathrm{~nm}$ to reduce its effect on the film properties.

\subsection{Solar cell production}

Both single junction and tandem thin film silicon cells were produced. Prior to the deposition of the single junction silicon cells, a $10 \mathrm{~nm}$ thin sputtered $\mathrm{ZnO}$ :Al layer was grown on the $\mathrm{SnO}_{2}$ samples in order to protect them from etching by the hydrogen plasma during the Plasma-Enhanced Chemical Vapour Deposition process for solar cell deposition. The $250 \mathrm{~nm}$ intrinsic amorphous silicon films were deposited at very high excitation frequencies ( $40 \mathrm{MHz}$ ) and at a substrate temperature of $200{ }^{\circ} \mathrm{C}$. The reactants were silane and hydrogen with phosphine and trimethylboron added for the $n$ and p-doped layers, respectively. The back contact was $\mathrm{ZnO}$ deposited by low-pressure CVD and a white dielectric was used as back reflector. Further details for this process have been published elsewhere [13].

For the micromorph cells the i-layer thicknesses are 270 and $1750 \mathrm{~nm}$, for the top amorphous and bottom microcrystalline cells, respectively. The i-layers consist of non-doped intrinsic amorphous and microcrystalline Si. These have different band-gaps and hence provide for a wider spectral response [1]. The doped layers are all made from $\mu c$-SiOx material, except for the top cell p-layer, which is a-SiC (due to the $\mathrm{SnO}_{2}: \mathrm{F}$ ). It is important to note that, in this case, no sputtered $\mathrm{ZnO}$ :Al was needed, as the process is soft enough not to cause the dramatic reduction of Sn, but provides good contact. Also, an intermediate reflector layer was used between the two subcells, made from $\mu \mathrm{c}-\mathrm{SiOx}$, and the back contact was sputtered $\mathrm{ZnO} / \mathrm{Ag}$. A schematic of the micromorph tandem is shown in Fig. 1 .

The single junction and micromorph cell sizes were $0.25 \mathrm{~cm}^{2}$ and $1 \mathrm{~cm}^{2}$ respectively.

\subsection{Characterisation}

The crystallinity and structure of the samples were assessed by $\mathrm{X}$-ray diffraction (Siemens D5000). The morphology and surface roughness of the samples were obtained by atomic force microscopy, AFM, (NanoScope IIIa, Digital Inst. Ltd). Film thickness was measured using a Dektak 3ST surface profiler on an etched step edge. Hall Effect measurements were performed on the $\mathrm{F}: \mathrm{SnO}_{2}$ films to determine the electrical properties with a lab built system using an electromagnet with a magnetic flux density of $0.84 \mathrm{~T}$. In order to determine the optical transmittance and the diffuse transmittance of the layers, a spectrophotometer (Perkin-Elmer Lambda 900) equipped with an integrating sphere was used. Solar cells were characterised by I-V measurements under a calibrated AM1.5G light source both under

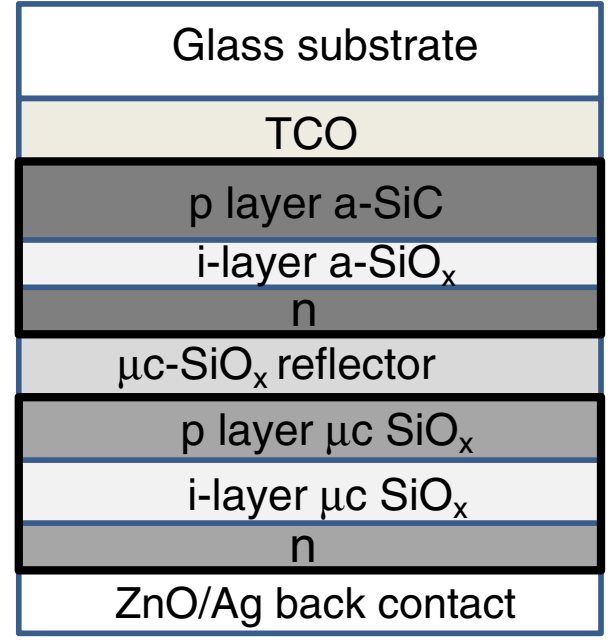

Fig. 1. Schematic of a micromorph tandem.

standard conditions for FF and Voc, and by spectral response measurements to extract the short circuit current, Jsc.

\section{Results and discussion}

The results section is divided into three main parts. Firstly, the effects of varying the APCVD tin precursor to water ratio on the physical, optical and electrical properties of the TCO thin film are discussed. Secondly, the importance of these on the characteristics of the solar cells is described. Finally, the cells fabricated with the optimised TCO were compared with cells from commercially available TCOs, both for efficiency and homogeneity over a $10 \mathrm{~cm} \times 10 \mathrm{~cm}$ substrate.

\subsection{TCO thin film analysis}

As can be seen from Fig. 2 there was some difference both in growth rate and roughness as a result of changing the tin to water ratio. Initially, the growth rate increased sharply before a more gradual increase with high water precursor levels, while the films generally became smoother.

Example AFM images (Fig. 3) show pyramidal surface features which became smaller at higher water precursor levels, which concurs with the lower observed Rms roughness. More quantitative analysis of feature height (Fig. 4a) and angle (Fig. 4b) revealed trends with the changes in the amount of water. Rougher films (i.e. low water) tended to show a broader height variation and mainly higher feature angle.

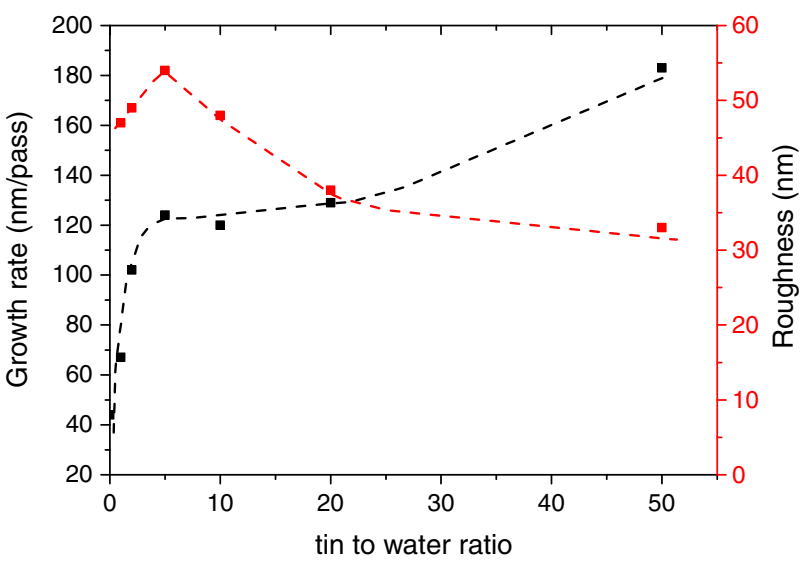

Fig. 2. Effects of the precursor tin to water ratio on the film growth rate, $\mathbf{w}$ and roughness (Rms), $\bullet$. (The dashed lines are guides for the eye). 

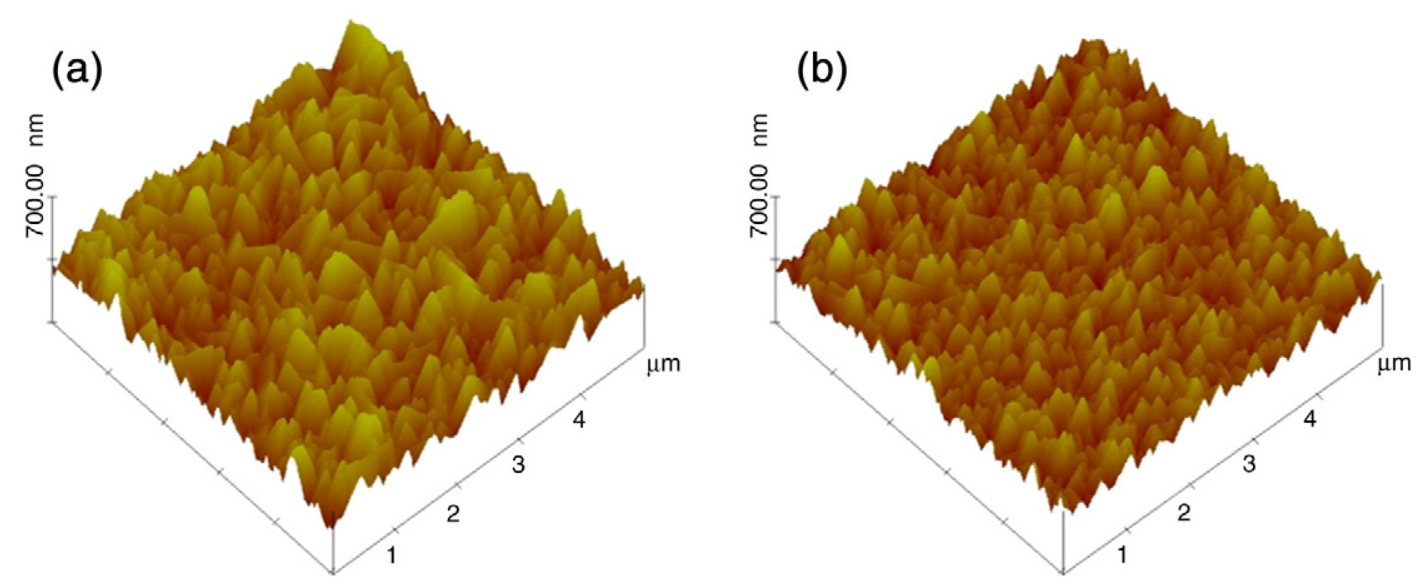

Fig. 3. AFM images ( $5 \mu \mathrm{m} \times 5 \mu \mathrm{m}$ ) of different $\mathrm{Sn}: \mathrm{H}_{2} \mathrm{O}$ ratios (a) $1: 2$ and (b) $1: 20$.

This fitted with previous work [11], where rougher films showed a higher angle of surface features and an increase in the number of bigger peak to trough heights.

Research reported by Zhao et al. [14] on the effects of water on the APCVD produced $\mathrm{SnO}_{2}: \mathrm{F}$ (no cell data) interestingly showed the inverse effect of larger feature sizes at higher water content, with increased compactness of the surface, suggesting increased smoothness (Roughness values were not given). They also stated that
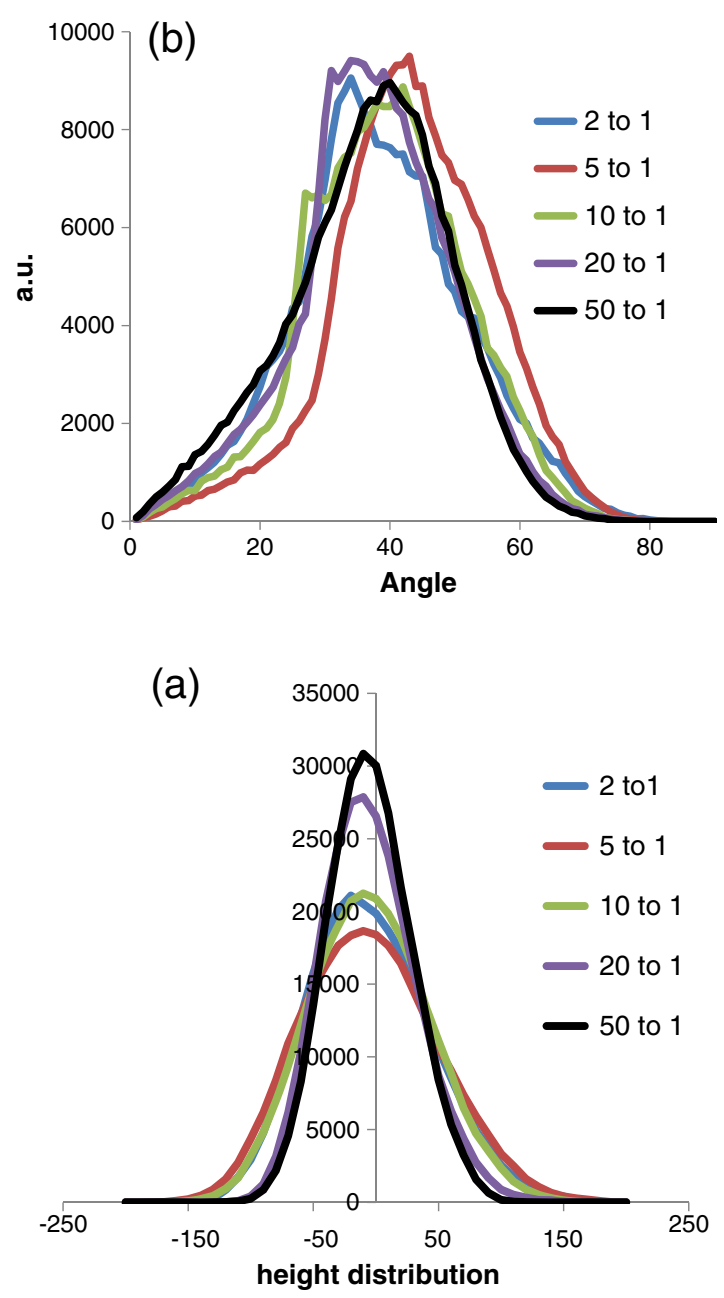

Fig. 4. Histograms of surface features for different $\mathrm{Sn}: \mathrm{H}_{2} \mathrm{O}$ ratios. (a) height, (b) angle. the film thickness and hence growth rate increased. However, film thickness increases themselves could be enough to change the morphology. They ascribe the changes to a decrease in activation energy, as the water concentration increases and hence a faster growth rate. Nicolay et al. [12] with ZnO:B also showed changes in the water/zinc precursor strongly affected the surface morphology, but not with a simple trend. They closely related these changes with change in the preferred crystallographic orientation. The final morphology is ascribed to flow-controlled growth competition between the different orientations present in the film at the beginning of the growth. However, in this paper the XRD, as discussed later, showed only small changes. Considering all the above, we could speculate that our results, which showed increased growth rate and smoothness at increased water/Sn precursor ratios, could relate to a change in the gas phase chemistry due to a reduced activation energy and/or increased prominence of some of the multiple of reactions taking place). This in turn leading to different chemical species reaching the surface and hence changes in surface morphology.

The electrical properties of our samples were all good with sheet resistances between $9 \Omega / \mathrm{sq}$ and $13 \Omega$ /sq and met the target of $\mathrm{N}<2 \times 10^{20} \mathrm{~cm}^{-3}$. This is important as a high doping level reduces thin film transparency which is one of the critical factors for PV cells. Ideally high carrier mobility is needed with low carrier concentrations [15]. The mobility increased with increasing water/Sn ratios (Fig. 5), with a general decrease in carrier concentration.

The decrease in carrier concentration with increasing water/Sn ratios could be due to a reduction in oxygen vacancies, which is one

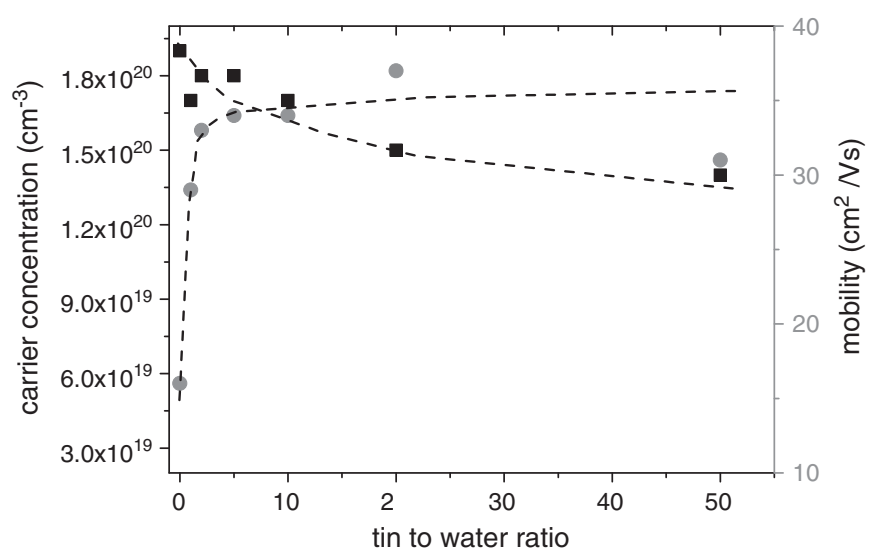

Fig. 5. Carrier concentration and mobility for different $\mathrm{Sn}: \mathrm{H}_{2} \mathrm{O}$ precursor ratios. (The dashed lines are guides for the eye). 


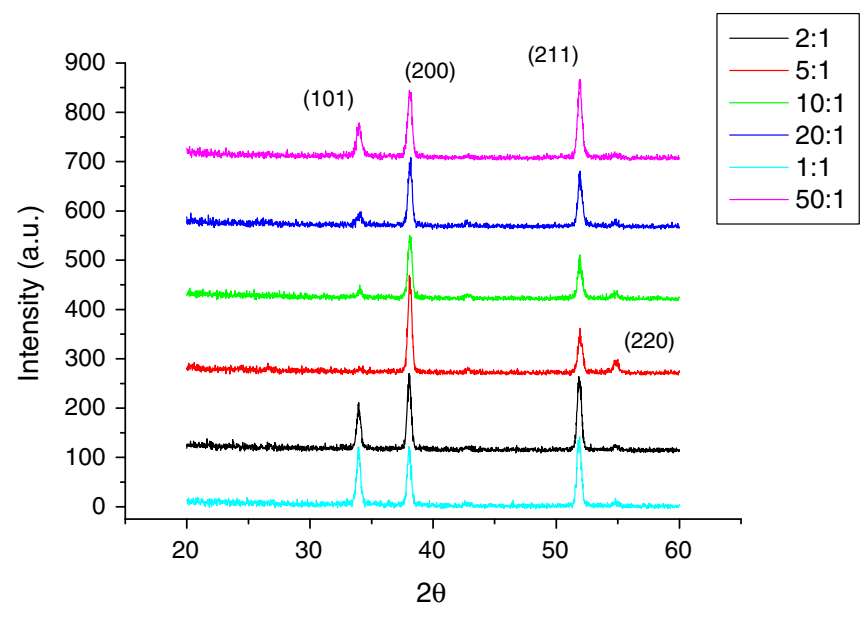

Fig. 6. X-ray diffraction of $\mathrm{SnO}_{2}: \mathrm{F}$ films deposited at different water:tin precursor ratios.

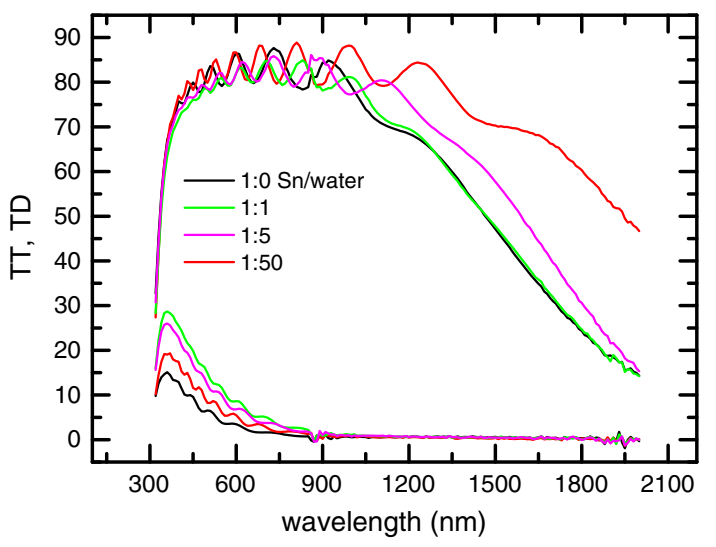

Fig. 7. Total and diffuse transmittances.

of the possible causes of bulk scattering phenomena at grain boundaries. The quality of the grain boundary has an effect, along with the doping level, on the carrier concentration. There are two possible mechanisms which control the mobility, the first relates to scattering within the grains and the second scattering at the grain boundaries. The carrier concentration determines which mechanism is the dominant factor. As the carrier concentration is reduced (at higher water/ Sn ratios) the grain boundaries become the more important factor and hence less effect on the mobility [16].

All X-ray spectra (Fig. 6) are very similar with strong (200) and (211) reflections, with weaker signals from the (220) and (101). There is a
Table 1

Best cell results on the different substrates.

\begin{tabular}{lllll}
\hline $\begin{array}{l}\text { Sn:water } \\
\text { precuror ratio }\end{array}$ & $\begin{array}{l}\text { Jsc EQE } \\
\left(\mathrm{mA} / \mathrm{cm}^{2}\right)\end{array}$ & $\begin{array}{l}\text { Efficiency \% } \\
(\text { Jsc from EQE) }\end{array}$ & $\begin{array}{l}\text { Voc } \\
(\mathrm{V})\end{array}$ & FF \\
\hline $\mathbf{1 : 5 0}$ & 15.1 & $\mathbf{1 0 . 1} \%$ & $\mathbf{0 . 9 1 5}$ & $\mathbf{0 . 7 3 1}$ \\
$1: 5$ & 15.03 & $9.5 \%$ & 0.904 & 0.700 \\
$1: 1$ & 15.12 & $8.8 \%$ & 0.899 & 0.645 \\
$1: 0$ & 14.4 & $6.5 \%$ & 0.873 & 0.518 \\
AGC-U & 14.8 & $\mathbf{9 . 4} \%$ & $\mathbf{0 . 9 0 8}$ & $\mathbf{0 . 7 0 3}$ \\
\hline
\end{tabular}

slight weakening of the (101) reflection relative to the (200) as the amount of water in the reaction is increased. Calculations of crystallite size, via Scherrers formula [17], showed little change for the (200) orientation $(\sim 25 \mathrm{~nm})$ while the (211) showed a small increase from $22 \mathrm{~nm}$ (1:1) to $29 \mathrm{~nm}$ (1:20) with little change beyond this level.

Use of higher water/Sn ratios, as discussed earlier, led to a smoothing of the surface morphology, which as expected led to a decrease in the diffuse transmittance (optical scatter) of high water precursor samples compared to those with lower water precursor content (Fig. 7). The total transmittance followed the trend of the measured free carrier concentration with the highest absorbing film being samples for $\mathrm{Sn} /$ water ratios of 1:0 and 1:1 which also shows the highest free carrier concentration. It is indeed well known that one of the main intrinsic TCO sources of doping is the oxygen atom vacancies which can be controlled by the water/Sn ratio.

\subsection{PV cell results}

To put our results into perspective the samples were compared to a high quality commercially available $\mathrm{SnO}_{2}: \mathrm{F}$ thin film AGC-U, which is generally considered to be the 'gold standard' for use in thin film PV solar cells. This is $1000 \mathrm{~nm}$ thick with an Rms roughness of $47 \mathrm{~nm}$. The electrical properties, as measured on our instrumentation, gave sheet resistance of $11 \Omega / \mathrm{sq}$, carrier concentration $1.7 \times 10^{20} \mathrm{~cm}^{-3}$ and mobility $33 \mathrm{~cm}^{2} \mathrm{~V}^{-1} \mathrm{~s}^{-1}$. Reference cells were fabricated on AGC-U concurrent to production of those on our TCO samples. This is particularly important as it reduces the possibilities of small variations due to deposition equipment and/or operators. For the initial screening a-Si:H single junction cells were fabricated.

The results on the cells are shown below in Fig. 8 . These show the mean and standard deviation for the best five cells, along with the maximum and minimum values, so a better statistical comparison between the cells present on each TCO sample is possible. From these graphs, it is seen that the best electrical properties were achieved with samples derived from high water content TCO precursor ratios, especially when considering the spread of the data, an indication of the homogeneity of the total sample (i.e. all layers). This is a further indication of the beneficial surface smoothening when using higher
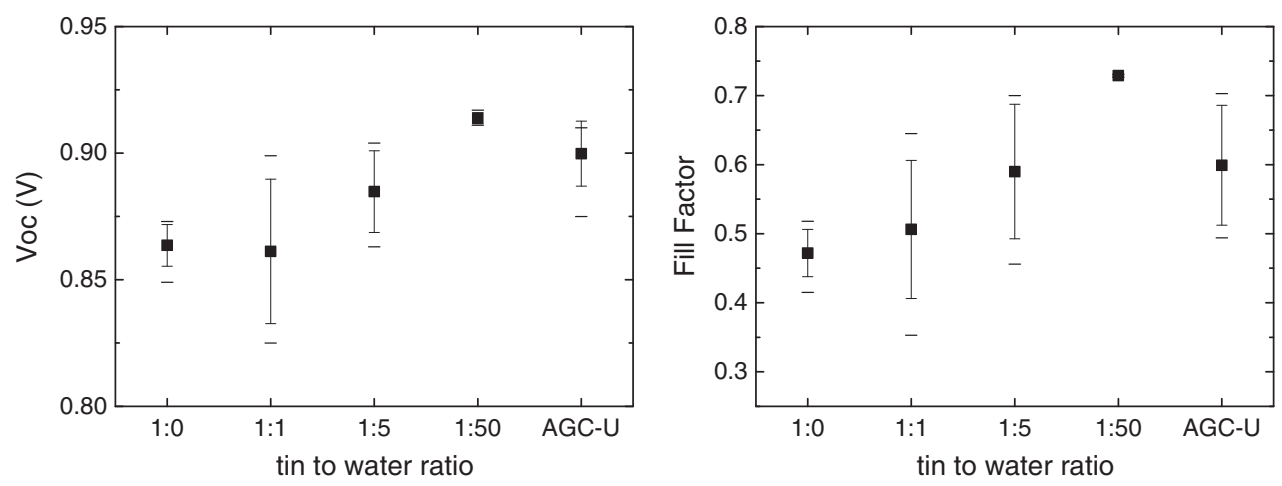

Fig. 8. Plots of open circuit voltage, $\mathrm{V}_{\mathrm{oc}}$, and the fill factor, $\mathrm{FF}$, for solar cells deposited with different precursor ratio. 


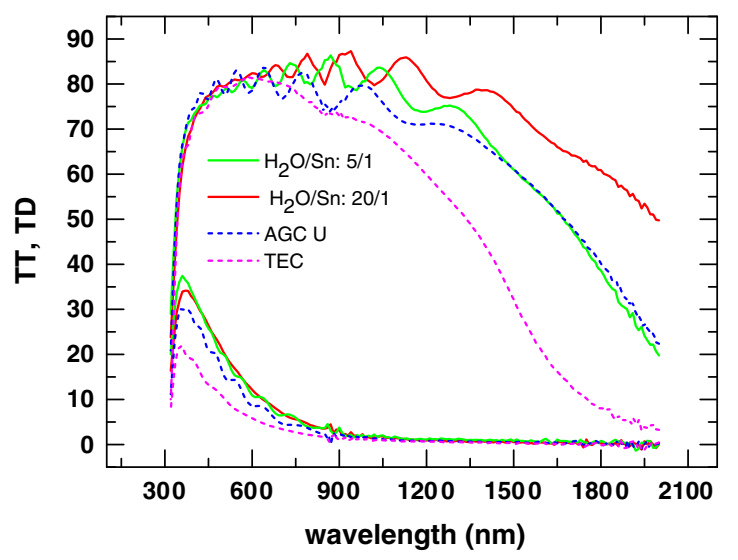

Fig. 9. Optical properties of industrial standards and of the APCVD TCO films.

water/Sn ratio. In any case, these results show that this sample produced cells that were better than the off-line industrial TCO AGC U and better than our previously optimised TCO with a precursor ratio of Sn:water 1:5.

Below is a summary table of the best cells measured on each substrate measured while using the photocurrent provided by the EQE (Table 1). It is seen that as expected from the higher $\mathrm{V}_{\mathrm{oc}}$ and FF, along with a higher current than expected considering the smoothing of the surface, the best efficiency was recorded on the sample with the highest water content ( $\mathrm{Sn}$ to water precursor ratio 1:50). Indeed, it led to an increase of $0.5 \%$ absolute efficiency ( $5 \%$ relative increase) when compared to the best results achieved on the AGC U substrate.

To confirm the results a selected second set of TCO samples, along with the commercial standards, were used to fabricate micromorph tandem cells. These cells are more time consuming and expensive to prepare so the initial screening process only used single junction cells. TCO films $(10 \mathrm{~cm} \times 10 \mathrm{~cm})$ deposited with water $/ \mathrm{Sn}$ ratio of 5/1 which had previously been our optimised film for PV and a high water/Sn ratio of 20/1 and to compare them against an industrial on-line product TEC 7 (NSG) TCO and an industrial high end off-line standard AGC-U TCO.

Prior to fabrication of the cells the optical and electrical properties of the new films were checked, which confirmed similarity to the previous results. The optical properties of our TCO are compared to the industrial standards, both on-line and off-line in Fig. 9. It can be seen that the mean total transmittance between 400 and $1100 \mathrm{~nm}$ goes from 76\% on the TEC 7 sample to $82 \%$ on our TCO samples. The haze (optical scatter) is higher than that of the commercial samples, but that of the high water sample is decreased from the 5:1 ratio sample. However, its relevance on cell performance for particularly increased current density is to be weighed against the rougher morphology associated to a high haze, rough morphology which leads to lower $\mathrm{V}_{\mathrm{oc}}$ and FF. Therefore, maximization of the haze factor should not be considered as the only solution to improve cell performances.

After fabrication of the cells, in order to test the homogeneity of the TCO surface the $10 \times 10 \mathrm{~cm}^{2}$ cell deposition was laser scribed into 20 smaller $1 \times 1 \mathrm{~cm}^{2}$ independent cells. The results of the new cells can be seen in Fig. 10. In the case of laser scribed cells the cell surface is very well defined and the photo-current measured with the IV setup is a reliable value (on the contrary to pen lift-off structuration technique in which the surface is ill defined and the current has to be taken from EQE measurements, which had been done for previous measurements).

It is seen that similar to the results achieved on the previously discussed lab scale substrates, the sample derived from the TCO deposited with the highest water content (water/Sn ratio of 20/1) provided the best $\mathrm{V}_{\mathrm{oc}}$ and $\mathrm{FF}$ characteristics while it also generated a lower current compared to the cell produced from the TCO deposited at water/Sn ratio of 5:1. Despite this, and as expected from previous results, the sample at the highest tested water/Sn ratio (20:1) provided

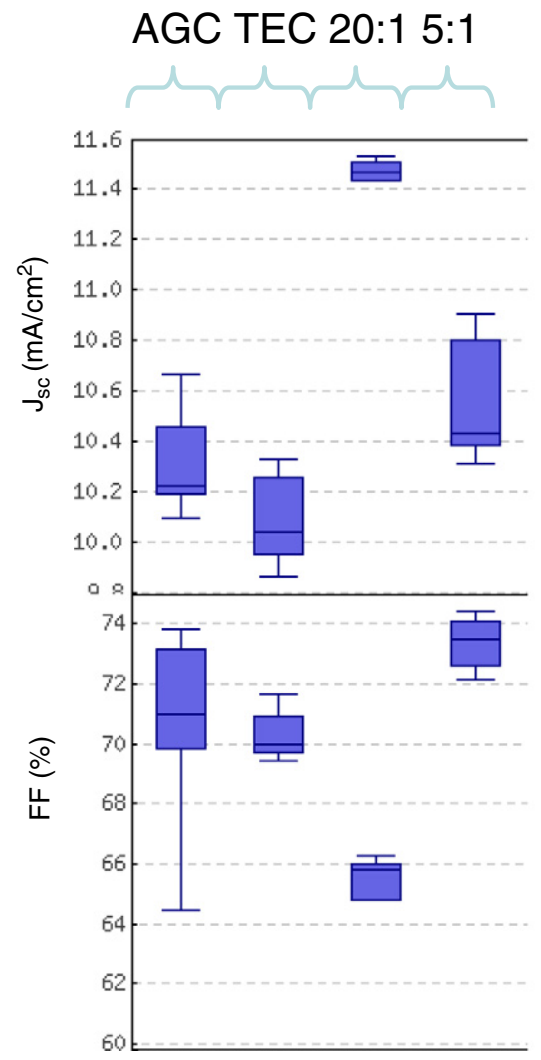

AGC TEC 20:1 5:1

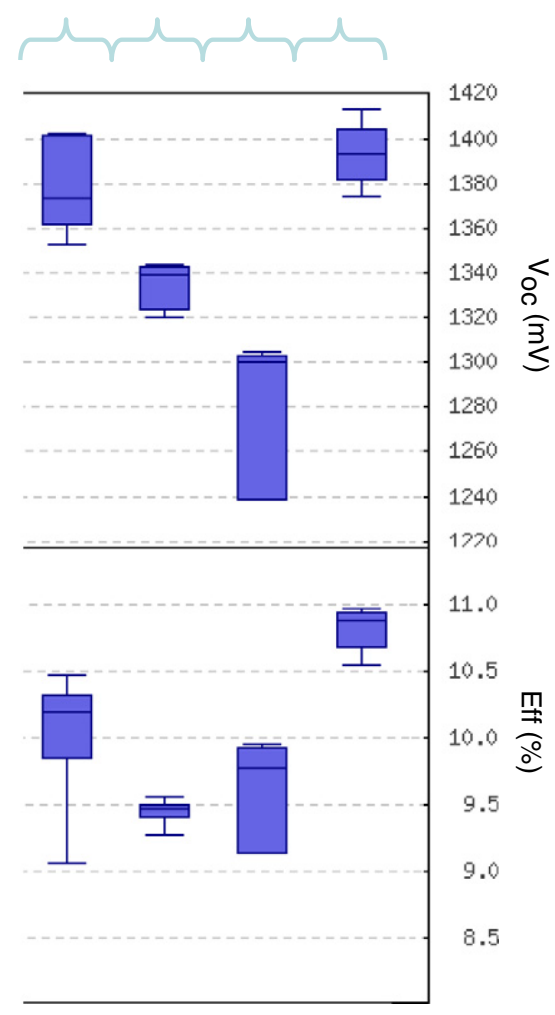

Fig. 10. Box plots of 20 solar cells on the different $10 \times 10 \mathrm{~cm}^{2}$ substrates. 
the best efficiency (mean on 20 cells) around $10.75 \%$ with a low result spreads indicating the good homogeneity of the substrate surface. The industrial on-line standard (to which our TCO was compared) showed efficiency close to $9.5 \%$, while the high end off-line industrial sample AGC U had a mean efficiency around $10.2 \%$.

There are several factors which contributed to the high efficiency of the final cell produced from the TCO deposited under conditions of high water/Sn ratio. Firstly, the lower carrier concentration, which led to a reduction in the free carrier absorption and hence greater transparency of the film allowing more light to reach the absorber layers. Secondly, the smoother surface of the TCO led to better interface integrity with the absorber layers and hence improved quality of the Si deposition and so a reduction in cell shunts.

\section{Conclusion}

A series of $\mathrm{SnO}_{2}: \mathrm{F}$ thin films have been deposited under different APCVD precursor ratios for Sn:water. These established that a high water to tin precursor ratio gave smoother, homogeneous films with higher carrier mobilities and optical transmittance. It has been clearly established that the use of a water-rich APCVD process was beneficial for the TCO as it led to higher $\mathrm{V}_{\text {oc }}$ and FF for the cells while still keeping sufficiently high photo-generated current. These in turn were shown to produce higher efficiency cells than two industrial produced products.

\section{Acknowledgments}

This work was financed by Framework 7 grant FP7 NMP CP-IP 214134-2 N2P "Flexible production technologies and equipment based on atmospheric pressure plasma processing for 3D nano-structured surfaces". The authors would like to thank Dr. Gabriel Onno from PVcomB/Helmholtz-Zentrum Berlin for preparation of the tandem micromorph solar cells.

\section{References}

[1] C. Beneking, B. Rech, S. Wieder, O. Kluth, H. Wagner, W. Frammelsberger, R. Geyer, P. Lechner, H. Rubel, H. Schade, Thin Solid Films 351 (1999) 241.

[2] J. Bailat, D. Dominé, R. Schlüchter, J. Steinhauser, S. Faÿ, F. Freitas, C. Bücher, L. Feitknecht, X. Niquille, T. Tschamer, A. Shah, C. Ballif, Proceedings of the IEEE World Conference on PV Energy Conversion, Waikoloa, HI, May, 2006.

[3] T. Dekker, J.W. Metselaar, R. Schlatmann, B. Stannowski, R.A.C.M.M. van Swaaij, M. Zeman, Proceedings of the 20th European Photovoltaic Solar Energy Conference (20th EU-PVSEC), June 6-10, 2005, p. 1517, (Barcelona, Spain).

[4] D. Knoesen, R.E.I. Schropp, W.F. Van der Weg, Proc. Mat. Res. Soc. Symp 377 (1995) 597.

[5] G. Bugnon, G. Parascandolo, T. Söderström, P. Cuony, M. Despeisse, S. Hänni, J. Holovský, F. Meillaud, C. Ballif, Adv. Funct. Mater. 22 (2012) 3665

[6] D.W. Sheel, H.M. Yates, P. Evans, U. Dagkaldiran, A. Gordijn, F. Finger, Z. Remes, M. Vanecek, Thin Solid Films 517 (2009) 3061.

[7] H.M. Yates, P. Evans, D.W. Sheel, U. Dagkaldiran, A. Gordijn, F. Finger, Z. Remes, M. Vanecek, Int. J. Nanotechnol. 6 (2009) 816

[8] H.M. Yates, P. Evans, D.W.U. Dagkaldiran, A. Gordijn, F. Finger, Z. Remes, M. Vanecek, ECS Trans. 25 (2009) 789.

[9] H.M. Yates, P. Evans, D.W. Sheel, Z. Remes, M. Vanecek, Thin Solid Films 519 (2010) 1334.

[10] I. Volintiru, A. de Graaf, J. van Deelen, P. Poodt, Thin Solid Films 519 (2011) 6258.

[11] H.M. Yates, P. Evans, D.W. Sheel, S. Nicolay, L. Ding, C. Ballif, Surf. Coat. Technol. 213 (2012) 167.

[12] S. Nicolay, M. Benkhaira, L. Ding, J. Escarre, G. Bugnon, F. Meillaud, C. Ballif, Sol. Energy Mater. Sol. Cells 105 (2012) 46.

[13] M. Despeisse, G. Bugnon, A. Feltrin, M. Stueckelberger, P. Cuony, F. Meillaud, A. Billet, C. Ballif, Appl. Phys. Lett. 96 (2010) 073507.

[14] H. Zhao, Q. Liu, Y. Cai, F. Zhang, Mater. Lett. 62 (2008) 1294.

[15] C. Agashe, O. Kluth, J. Hupkes, U. Zastrow, B. Rech, M. Wuttig, J. Appl. Phys. 95 (2004) 1911.

[16] S. Fay, J. Steinhauser, S. Nicolay, C. Ballif, Thin Solid Films 518 (2010) 2961.

[17] B.D. Cullity, Elements of XRD, Addison-Wesley, 1978. 